\title{
The metabolic syndrome among Danish seafarers
}

\section{Sanne Fribo Møller Pedersen, Jørgen Riis Jepsen}

Centre of Maritime Health and Society, Institute of Public Health, University of Southern Denmark, Esbjerg, Denmark

\begin{abstract}
Background: Representing a cluster of risk factors related to insulin resistance, the metabolic syndrome (MS) is defined by a constellation of increased waist circumference in combination with dyslipidaemia, hyperglycaemia, and/or increased blood pressure. MS is a strong risk factor for a number of chronic diseases, including diabetes and cardiovascular conditions. Approximately $1 / 5$ of Danish adults have MS, which has an etiological relation to nutritional factors, sleep patterns, work-related stress, fatigue, and physical activity - all of which are critical issues at sea.

Materials and methods: Out of 655 Danish seafarers attending medical fitness examination by seafarers' doctors in 4 clinics, 524 participants (mean age of 38.5 years) underwent waist circumference measurements and provided questionnaire information about their workplace on board and their consumption of tobacco and alcohol. Blood samples were taken if waist circumference was increased. MS was defined according to the International Diabetes Federation as central obesity in combination with 2 out of the following conditions: elevated triglycerides, blood pressure, fasting plasma glucose, and reduced HDL-cholesterol (or treated hyperlipaemia or hypertension, or previously diagnosed type 2 diabetes, respectively). Results: The crude baseline prevalence of MS was $25.9 \%$ among male and $10.7 \%$ among female Danish seafarers. $30.6 \%$ were current smokers. The alcohol consumption was comparable to that of Danes ashore, but exceeded recommendations of $18.6 \%$.

Conclusions: MS was increased in this young group of seafarers. Seafarers with MS were advised to $10 \%$ weight-reduction, physical activity 1/2 hour/day, reduced intake of saturated fat and increased fibres in diet, smoking cessation, and control of alcohol consumption as an intervention measure. Follow-up will take place after 2 years.
\end{abstract}

(Int Marit Health 2013; 64, 4: 183-190)

Key words: metabolic syndrome, seafarers, nutrition, smoking, alcohol consumption, Denmark

\section{INTRODUCTION}

The metabolic syndrome (MS) represents a cluster of risk factors related to insulin resistance. MS is defined by the International Diabetes Federation as a constellation of increased waist circumference in combination with dyslipidaemia, hyperglycaemia, and/or increased blood pressure (BP) [1]. The prevalence of MS is rising in a global perspective [1], and MS is currently present in $1 / 5$ of the adult Danish population [2]. MS is a strong predictor for type 2 diabetes and cardiovascular diseases by increasing the risk 6 and 5 times, respectively [3]. It contributes to $1 / 3$ of all cardiovascular diseases and increases the cardiovascular mortality by a factor of 2 [4]. In addition, MS is strongly as- sociated to arterial hypertension, non-alcoholic fatty liver, polycystic ovary syndrome and certain cancers.

A striking increase in the worldwide number of people with MS has taken place [3]. There is a social gradient in the prevalence of MS. In addition, it has been shown that the distribution within the 2 sexes differs in various populations. In Denmark, males who represent the majority of seafarers have a higher prevalence than females. There is also a difference in the relative susceptibility between various populations. Asians currently represent a major and increasing proportion of seafarers on Danish flagged ships, and this group of seafarers seem to be in particular risk of MS [5, 6]. MS has a strong etiological relation to nutritional factors, 
sleep patterns and shift work [7], work-related stress [8], fatigue [9], and physical activity - all critical issues at sea.

For being cleared fit for work on board a ship, seafarers are required to pass medical examination every second year. While this examination may potentially represent an active health-based selection leading to seafarers being healthier than the rest of the population, it is not known whether a "healthy worker" selection does in fact take place consequent to the health examinations. If so, it is also unknown which health factors are influenced and to what extent [10]. In this context, it should be emphasised that health data that are currently collected during the medical fit for duty examinations, such as, e.g. body mass index (BMI), $\mathrm{BP}$ and urine analysis for glucose, are meant to safeguard the safety of the crew and the vessel, rather than promoting the health of seafarers.

During the last decades, morbidity data on Danish seafarers have caused concern. Hospitalisations due to chronic conditions that can be related to lifestyle are more frequent among seafarers than in the general population [11, 12]. An increased cardiovascular mortality of Danish seafarers was demonstrated in 1996 [13] and again in a recent study, in which disease-related deaths - in particular from cardiovascular conditions - continue to represent the dominant mode of death in the maritime setting [14].

Recent studies have demonstrated even more overweight in Danish seafarers than in the general Danish population, which is also severely affected by weight problems. The rate of overweight has increased during the last decade, and overweight is currently present in the majority of Danish seafarers (66\% in 2010) [15]. Furthermore, maritime students who enter the maritime business are already more overweight than other young people [16].

While the increased waist circumference in MS may represent 1 aspect of obesity, however, the 2 concepts differ. Obesity may occur in persons that are metabolically healthy [17] and a person within normal weight limits may still have increased waist circumference and share other characteristics of MS. Approximately half of the subjects with $\mathrm{MS}$ have a $\mathrm{BMI}<30 \mathrm{~kg} / \mathrm{m}^{2}[18]$.

MS represents an important - and preventable - public health issue that is widespread among Danes. To our knowledge, MS has never been studied in representative samples of seafarers, but recently $51 \%$ of seafarers in 2 Danish shipping companies were defined as having MS [19]. Studies of occupational groups such as construction workers [20], policemen [21] and law enforcement personnel [22] have demonstrated high rates of MS from $21 \%$ to $26.7 \%$. Comparisons between MS in occupational groups suggested transport workers to be in particular risk [23]. The perspectives of secondary prevention are illustrated by a 3-year follow-up of Japanese workers with 1 or 2 components for
MS that showed odds-ratios of 3.1 and 7.8, respectively, for subsequent development of MS [24].

The assessment of the prevalence of MS among seafarers would be an appropriate starting point for a preventive intervention on all levels, since MS represents a serious risk factor, which can potentially be modified and should therefore be addressed. Reducing the prevalence of MS may be more efficient than, e.g. an isolated focus on weight reduction, because a moderately increased BMI of a physically fit person does not, in itself, call for intervention. It has been demonstrated that a significant proportion of obese subjects are metabolically healthy [17]. Still, an intervention targeting overweight has been regarded as of importance [19], but although worksites are potential important locations for weight management programs, most studies have not yet demonstrated substantial mean rates of weight loss and sustainability of intervention programs. Further studies are needed to demonstrate effective worksite weight loss interventions and to quantify their sustainability [25].

The management of MS is primarily based on the treatment of an actual discovered disease such as manifest hypertension or diabetes, which may represent components of MS that the seafarer may not have been previously aware of. Secondary prevention should aim to eliminate or reduce external risk factors by improving the seafarer's dietary habits and options, and by increasing the level of physical activity. An intervention addressing the additional risk imposed by smoking and alcohol consumption is also appropriate. Interventions addressing psychosocial issues on board present a major challenge that also has to be addressed. Secondary prevention by individual counselling may be combined with a health promotion effort directed to risk environments such as a single vessel, a shipping company or a seafaring community.

The current study was designed as a follow-up study with an intervention introduced in this first part, which represents a baseline study of the prevalence and distribution of MS among Danish seafarers. In addition, we wanted to study seafarers' consumption of tobacco and alcohol due to the contribution of these habits to the risks associated with MS.

\section{MATERIALS AND METHODS}

This study has applied the definition of MS from the International Diabetes Federation (Table 1) [1].

The study complied with the Helsinki Declaration and was approved by the local Ethics Committee (Ref. no. S-20110039). Signed informed consent was obtained from all the participants.

\section{MATERIALS}

The baseline data were collected from the beginning of October 2011 until the end of June 2012 by 4 authorised 
Table 1. Definition of metabolic syndrome according to the criteria by the International Diabetes Federation

\begin{tabular}{llc}
\hline Factor & \multicolumn{1}{l}{ Criteria } & \multicolumn{1}{c}{ Women } \\
\cline { 2 - 3 } & Men & $\geq 80 \mathrm{~cm}$ \\
\hline $\begin{array}{l}\text { Increased waist circumference } \\
\text { Plus any } 2 \text { of the following factors: }\end{array}$ & $\geq 94 \mathrm{~cm}$ & $>1.7 \mathrm{mmol} / \mathrm{L}$ \\
$\begin{array}{l}\text { Raised triglycerides } \\
\text { or specific treatment for this lipid abnormality }\end{array}$ & $<1.03 \mathrm{mmol} / \mathrm{L}$ & $<1.29 \mathrm{mmol} / \mathrm{L}$ \\
$\begin{array}{l}\text { Reduced high density lipoprotein-cholesterol } \\
\text { or specific treatment for this lipid abnormality }\end{array}$ & Systolic $\geq 130 \mathrm{~mm} \mathrm{Hg}$ or diastolic $\geq 85 \mathrm{~mm} \mathrm{Hg}$ \\
$\begin{array}{l}\text { Raised blood pressure } \\
\text { or treatment of previously diagnosed hypertension } \\
\text { Raised fasting blood plasma glucose } \\
\text { or previously diagnosed type } 2 \text { diabetes }\end{array}$ & \\
\end{tabular}

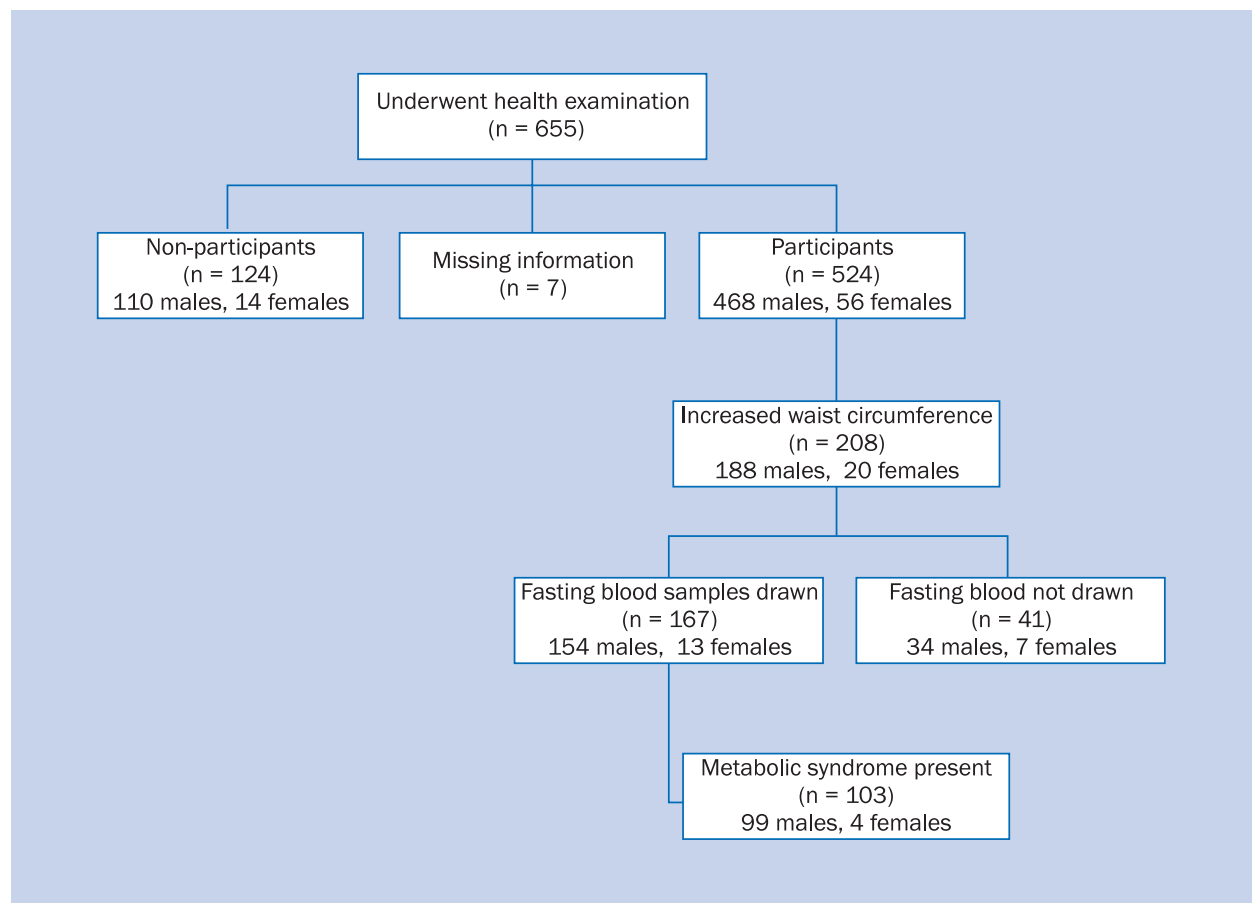

Figure 1. Flowchart illustrating the studied sample of the seafarers

seafarer's doctors' clinics in Denmark. 655 Danish seafarers who consulted these clinics for medical fitness examination were given written and verbal information about the ongoing project and invited to participate. 527 seafarers accepted the invitation. The non-participants underwent the usual medical examination of seafarers.

Figure 1 presents a flowchart illustrating the sampling. Out of 128 non-participating seafarers, there was missing information for 4 persons about sex $(n=1)$, date of birth (DOB) $(n=2)$, and both sex and DOB $(n=1)$, resulting in 124 non-participating seafarers that were available for the descriptive information. Out of 527 participating seafarers, 3 seafarers were excluded because of missing information about sex $(n=1), \operatorname{DOB}(n=1)$, and non-fasting glucose value $(n=1)$, respectively. Consequently, data from 524 seafarers were used for the final analyses (Fig. 1).

Forty one of the participating seafarers with increased waist circumference were not fasting on arrival to the medical examination, and due to imminent embarkation they had no opportunity for having a blood sample drawn at a later time. Consequently, missing laboratory data of these seafarers did not permit classification with respect to MS (Table 1). However, assuming the same distribution of MS among the seafarers who could not provide fasting blood samples as among those who did, it was possible to estimate the prevalence of MS in the total sample. 
Table 2. Demographic characteristics of study participants vs. non-participants, respectively

\begin{tabular}{|c|c|c|c|c|c|c|c|c|c|c|c|c|}
\hline & \multicolumn{6}{|c|}{ Study participants $(n=524)$} & \multicolumn{6}{|c|}{ Non-participants $(n=124)$} \\
\hline & \multicolumn{3}{|c|}{ Males $(n=468,89 \%)$} & \multicolumn{3}{|c|}{ Females $(n=56,11 \%)$} & \multicolumn{3}{|c|}{ Males $(n=110,89 \%)$} & \multicolumn{3}{|c|}{ Females $(n=14,11 \%)$} \\
\hline & $\mathbf{N}$ & Mean (SD) & Range & $\mathbf{N}$ & Mean (SD) & Range & $\mathbf{N}$ & Mean (SD) & Range & $\mathbf{N}$ & Mean (SD) & Range \\
\hline Age [years] & 468 & $38.5(13)$ & $16-72$ & 56 & $31.6(10.8)$ & $16-67$ & 110 & $41.5(14.6)$ & $17-77$ & 14 & $39.9(9.1)$ & $26-51$ \\
\hline BMI $\left[\mathrm{kg} / \mathrm{m}^{2}\right]$ & $455^{*}$ & $26.3(4.3)$ & $17-55.6$ & $53^{*}$ & $24.5(4.2)$ & $18-40.4$ & $107^{*}$ & $28(5)$ & $19.4-45.9$ & $13^{*}$ & $25(3.5)$ & $19-30.5$ \\
\hline $\begin{array}{l}\text { Waist circum- } \\
\text { ference }[\mathrm{cm}]\end{array}$ & $467 *$ & $93.5(11.7)$ & $68-140$ & 56 & $81.8(13.4)$ & $64-122$ & - & - & - & - & - & - \\
\hline
\end{tabular}

\section{METHODS}

The waist circumference was measured as the horizontal circumference of the body, midway between the lower rib and the topmost iliac crest. Seafarers with a waist circumference exceeding the limits for defining MS (Table 1) proceeded to have fasting blood samples drawn for analysis for triglycerides, high density lipoprotein (HDL)-cholesterol, and glucose. Individuals who were not fasting at the health examination were asked to come back later or to consult their general practitioner for fasting blood samples.

The following data were recorded for participants as well as non-participants: sex, DOB, height and weight. For each individual seafarer, the age and BMI was calculated from the information on DOB and height/weight, respectively.

The participants were interviewed about their workplace on board (machine, bridge, catering, and other), and about the anamnestic criteria included in the definition of MS (Table 1), i.e. treatment of previously diagnosed lipid abnormalities and hypertension, and previously diagnosed type 2 diabetes. They were additionally questioned about their smoking and drinking habits onshore and on board, respectively.

\section{STATISTICAL ANALYSIS}

The data were analysed using the statistics package from IBM SPSS Statistics ver. 19 with demographic data presented by descriptive statistics and categorical variables presented with numbers ( $\mathrm{n}$ ) and percentage (\%). Continuous variables are presented with mean and standard deviation (SD), minimum (min) and maximum (max) values.

\section{REPRESENTATIVENESS}

The representativeness of the studied seafarers depends on: a) whether the study participants differ from the non-participants, and b) whether the seafarers who attended 4 participating seafarers' clinics differ from all the seafarers who consult a seafarers' doctor for medical certification.
To test the study sample for representativeness, the means for age, BMI, and the distribution of sex for the participants were compared to the corresponding data for the non-participants and for all Danish seafarers' who had health examinations from July $1^{\text {st }}, 2010$ to June $30^{\text {th }}, 2011$, respectively.

\section{RESULTS}

\section{REPRESENTATIVENESS OF THE SAMPLE}

Table 2 illustrates the demographics for the study participants and non-participants, respectively. The distribution of the participating seafarers with regard to sex, age and $\mathrm{BMI}$ was very similar to that of the non-participants. There was, however, a tendency towards higher age, as well as higher BMI in non-participants. In particular, we noted a difference in the age groups 25-44 years/45-64 years for which the relative frequencies were $51.0 \% / 30.3 \%$, respectively, among participants and 40.3\%/41.1\%, respectively, among non-participants.

Almost half of all the seafarers worked on the bridge. The percentage of participants and non-participants working on the bridge was identical for 2 groups (45.2\%). For the machine crew and the groups catering and "other", the distribution among participants and non-participants was $22.6 \% / 10 \%, 9.7 \% / 14.5 \%, 15.6 \% / 22.6 \%$, respectively.

The mean age in the study sample and in the comparison group of all Danish seafarers subjected to health examinations during 1 year was 38.4 years (SD 13.3) and 40.2 years (SD 14.3), respectively. The mean BMI in the study sample was $26.4 \mathrm{~kg} / \mathrm{m}^{2}$ (SD 4.5) and in the comparison group $27 \mathrm{~kg} / \mathrm{m}^{2}$ (SD 4.9). With a contribution of males of $89.1 \%$ and $86.4 \%$ in the study sample and the comparison group respectively, the distribution of sex was also similar in 2 groups.

Table 3 illustrates the data that contribute to the definition of MS: a) information provided by the participants regarding the conditions that are included in the criteria for MS, b) waist circumference and blood pressure, and c) laboratory data (Table 1). 
Table 3. Baseline characteristics (anamnestic, physical and laboratory data) of the participating seafarers

\begin{tabular}{|c|c|c|c|c|}
\hline & \multicolumn{2}{|l|}{ Males $(n=468)$} & \multicolumn{2}{|l|}{ Females $(n=56)$} \\
\hline & $\begin{array}{l}\text { No. exceeding the } \\
\text { IDF criteria (\%) }\end{array}$ & No. examined** & $\begin{array}{l}\text { No. exceeding } \\
\text { the IDF criteria (\%) }\end{array}$ & No. examined** \\
\hline Central obesity (Europids) & $188(40.2)$ & 467 & $20(35.7)$ & 56 \\
\hline Raised triglycerides* & $62(13.2)$ & 153 & 0 & 13 \\
\hline Specific treatment for hypertriglyceridaemia & $2(0.4)$ & 458 & 0 & 55 \\
\hline Reduced HDL-cholesterol* & $34(7.3)$ & 153 & $3(5.4)$ & 13 \\
\hline Specific treatment for hypo-HDL-cholesterolaemia & $19(4.1)$ & 458 & $1(1.8)$ & 55 \\
\hline Elevated blood pressure & $306(65.4)$ & 451 & $26(46.4)$ & 54 \\
\hline Treatment of previously diagnosed hypertension & $35(7.5)$ & 461 & $2(3.6)$ & 55 \\
\hline Raised fasting blood plasma glucose* & $84(17.9)$ & 153 & $4(7.1)$ & 12 \\
\hline Previously diagnosed type 2 diabetes & $9(1.9)$ & 461 & 0 & 55 \\
\hline
\end{tabular}

*Participants who had fasting blood samples drawn; **slightly diverging due to missing data; IDF - International Diabetes Federation; HDL - high density lipoprotein

Table 4. The number and prevalence of metabolic syndrome (MS) with age and sex of the participants

\begin{tabular}{|c|c|c|c|c|c|c|c|c|}
\hline \multirow[t]{2}{*}{ Age [years] } & \multicolumn{2}{|c|}{ All participants (n) } & \multicolumn{3}{|c|}{$\begin{array}{l}\text { Male participants with fasting blood } \\
\text { samples }(n=154)\end{array}$} & \multicolumn{3}{|c|}{$\begin{array}{l}\text { Female participants with fasting blood } \\
\text { samples }(n=13)\end{array}$} \\
\hline & Male & Female & $\mathbf{n}$ & MS (n) & $\begin{array}{l}\text { Prevalence } \\
\text { of MS (\%) }\end{array}$ & $\mathbf{n}$ & MS (n) & $\begin{array}{l}\text { Prevalence } \\
\text { of MS (\%) }\end{array}$ \\
\hline$<18$ & 5 & 1 & 0 & - & - & 0 & - & - \\
\hline $18-24$ & 67 & 16 & 1 & 1 & 1.5 & 3 & 1 & 6.3 \\
\hline $25-44$ & 236 & 31 & 69 & 42 & 17.8 & 8 & 2 & 6.5 \\
\hline $45-64$ & 152 & 7 & 78 & 51 & 33.6 & 2 & 1 & 14.3 \\
\hline$\geq 65$ & 8 & 1 & 6 & 5 & 62.5 & 0 & - & - \\
\hline Total & 468 & 56 & 154 & 99 & 21.4 & 13 & 4 & 7.4 \\
\hline
\end{tabular}

Out of 167 seafarers who provided fasting blood samples, 103 fulfilled the criteria for MS at baseline (Table 4). The prevalence for male seafarers increased with age. The prevalence of MS among seafarers who provided fasting blood samples was $99 / 154 \times 100=64.3 \%$ for males, and $4 / 13 \times 100=30.8 \%$ for females. Due to the proportion of seafarers who had not provided blood samples, calculation of the prevalence by using as the numerator the seafarers with MS and as the denominator the total number of participating seafarers will underestimate the true prevalence.

Assuming the same distribution of MS among the 41 seafarers (34 males and 7 females) who could not provide fasting blood samples as among the seafarers with increased waist circumference who did, the number of seafarers with MS among the former can be estimated to $34 \times 64.3 / 100$ $=22$ male and $7 \times 30.8 / 100=2$ female seafarers, respectively.

This calculation resulted in an estimation of presence of MS being in $99+22=121$ male and $4+2=6$ female seafarers in the total sample of participants. Accordingly, the total prevalence of MS was calculated to 121/468 $\times 100=25.9 \%$ and $6 / 56 \times 100=10.7 \%$ for male and female seafarers, respectively. For both sexes together, the estimated prevalence was $24.2 \%$.

\section{CONSUMPTION OF TOBACCO AND ALCOHOL}

The questionnaire information about smoking and alcohol habits is presented in Tables 5 and 6. Current smokers represent $30.6 \%$ of the studied seafarers (Table 5 ). Only few seafarers drink while on board the vessel, while the majority does drink alcoholic beverages ashore (Table 6).

\section{DISCUSSION}

We have demonstrated that MS is present significantly $(24.2 \%)$ in the studied sample of Danish seafarers. Is this prevalence alarming? The crude figure approaching a quarter of the Danish seafarers may seem rather reassuring when compared to other published figures.

Cameron et al. (2004) [26] has reviewed a number of studies of MS from various parts of the world and found a geographically highly variable prevalence and age and sex distribution. However, different definitions of MS complicate the comparisons. 
Table 5. Tobacco consumption while ashore and on board, respectively, for 523 participating seafarers who provided this questionnaire information (\% of questionnaire responders)

\begin{tabular}{|c|c|c|c|c|c|c|}
\hline $\begin{array}{l}\text { Never } \\
\text { n (\%) }\end{array}$ & $\begin{array}{l}\text { Previous smoker } \\
\text { n (\%) }\end{array}$ & $\begin{array}{l}\text { Current s } \\
\text { n (\%) }\end{array}$ & & & & \\
\hline \multirow[t]{4}{*}{$240(45.9)$} & \multirow[t]{4}{*}{$123(23.5)$} & \multicolumn{5}{|c|}{$160(30.6)$} \\
\hline & & \multicolumn{2}{|l|}{ Ashore } & \multicolumn{3}{|c|}{ On board* } \\
\hline & & $<15 g$ & $>15 g$ & $0 \mathrm{~g}$ & $<15 g$ & $>15 g$ \\
\hline & & 84 (16.1) & 76 (14.5) & $4(0.8)$ & 80 (15.3) & 75 (14.3) \\
\hline
\end{tabular}

$* 1$ cigarette $=1 \mathrm{~g} ; 1$ pipe of tobacco $=1 \mathrm{~g} ; 1$ cheroot $=3 \mathrm{~g} ; 1$ cigar $=5 \mathrm{~g}$.

*1 seafarer did not quantify smoking on board.

Table 6. Alcohol consumption for 511 and 497 participating seafarers who provided the questionnaire information about alcohol habits ashore and on board, respectively (\% of questionnaire responders)

\begin{tabular}{lllll}
\hline & \multicolumn{4}{l}{ Weekly consumption of units of alcohol $\mathbf{n}(\%)$} \\
\cline { 2 - 5 } & $\mathbf{0}$ & $\mathbf{1 - 7}$ & $\mathbf{8 - 1 4}$ & $\mathbf{2 1 5}$ \\
\hline Ashore & $54(10.6)$ & $246(48.1)$ & $116(22.7)$ & $95(18.6)$ \\
On board & $443(89.1)$ & $38(7.6)$ & $16(3.2)$ & -
\end{tabular}

For comparison with other Danish samples, the prevalence of MS among 3,303 persons in the general Danish population was calculated to $29.6 \%$ [27]. In another Danish population sample with a median age of 51 (41-74) years studied, the prevalence of MS based on the International Diabetes Federation criteria was 23.8 for men and 16.1 for women [28]. In a study of Danish psychiatric outpatients, the comparison group of a random sample of individuals of 18-69 years, but with a higher participation rate for the older age groups, resulted in a prevalence of $29.6 \%$. The comparison of these studies with our figures, however, should take into account that the studied population of seafarers is characterised by their relatively young age (mean age 38.5 years). This is of importance since a strong gradient has been demonstrated in all studies, including this one, of an increasing prevalence of MS with age. Furthermore, a strong inverse social gradient in the prevalence of MS has been demonstrated in a recent Danish study [2]. Our study involved a mixed group of seafarers, most of which were officers, and therefore representing higher social strata, for which one would expect a smaller prevalence of MS. However, we have not stratified according to social factors. Taken together, the composition of our sample representing mostly younger seafarers most of which belong to the officer group suggests that the demonstrated prevalence of MS is a cause for concern.

\section{SELECTION}

To conclude that the prevalence of MS in this study is representative for Danish seafarers in general, we have de- monstrated that the participating seafarers are reasonably comparable to the non-participating seafarers with regard to sex, age, and BMI. The workplaces on board were also similar for the participating vs. non-participating seafarers. However, some differential selection may have taken place with regard to the latter with more dropouts among females belonging to catering staff. The comparison of demographic data and BMI of the seafarers in this sample with the national wide collected data from all medical examinations of seafarers during a 1-year period indicates that the studied sample is representative.

However, the relatively higher number of elderly seafarers and a slightly higher BMI among non-participants suggest a selection that is likely to cause an underestimation of the true prevalence of the seafarers with MS (Table 2). Therefore, with an acceptable certainty, we can say that the calculation of the prevalence of MS among Danish seafarers represents a rather accurate minimum value.

\section{CONSUMPTION OF TOBACCO AND ALCOHOL}

It is encouraging to note, that the reported alcohol consumption and smoking is limited, although still exceeding that of other Danes. This is a fierce change compared to previous conditions. Several previous Danish studies have shown the heavy health impact of smoking and alcohol consumption among Danish seafarers [13, 29-31].

The reported rate of current smokers is now almost at the level of that of Danes, out of which $25 \%$ were smokers in 2005. This reduction of smoking at sea has taken place in spite of easy access to cheap duty free cigarettes in overseas shipping.

The consumption of alcohol is now regulated for Danish seafarers in active duty (similar to regulations relating to land-traffic). According to the seafarers' responses, drinking on board is now limited. Still, however, seafarers' reported alcohol habits are also comparable to those of Danish adults. In 2005, $17.9 \%$ of Danish men and $10.8 \%$ of women consumed an amount of alcohol in excess of the authorities' previous recommendations of 21/14 units/week, respectively, for men and women. This recommendation has now been 
further reduced to $14 / 7$ units/week. If the 14-unit limit for men is applied, $18.6 \%$ of the seafarers exceed the Danish health authorities' current weekly maximal recommended consumption while ashore.

Cigarette smoking seems to be an independent risk factor for MS while the risk does not seem to be exaggerated by alcohol intake [32]. However, the additional caloric intake from alcoholic beverages contributes to the metabolic balance.

\section{PERSPECTIVES IN TERMS OF SEAFARERS' HEALTH IN DANISH MERCHANT SEAFARING}

The presented results must be seen in the context of the contemporary manning of the Danish merchant fleet. Today, the majority of Danish seafarers are officers. Consequently, officers represent the majority of seafarers in the studied sample. More importantly, this study has addressed only Danish seafarers and not the foreign crew that today represents a majority of seafarers on Danish merchant vessels. A recent Danish study [2] demonstrated a strong inverse social gradient in the prevalence of MS, with higher prevalence in less skilled occupations and less occurrence among professionals.

The prevalence of MS among foreign crews is not known, but we are concerned that MS may be more prevalent in foreign seafarers on Danish ships. More severe consequences of MS, in particular for many Asians, who are more prone to diseases such as type 2 diabetes and more exposed to an imbalanced consumption of fats and oils [33], are likely. Deficient health control and management in their home countries are likely to further aggravate the situation.

Taking into account the higher risk of MS in Asian seafarers $[5,6]$ that today represent the majority of the ratings on board Danish ships, one would expect MS to be considerably more frequent if this study was extended to cover crews of any nationality and consequently a higher share of ratings with other than Danish citizenship.

This baseline study will be followed by an intervention consisting of offering treatment to seafarers with MS when indicated, and of providing appropriate counseling with regard to health. The basic advice to subjects with MS consists of $10 \%$ weight-reduction, physical activity $1 / 2$ hour per day, reduced intake of saturated fat and increased content of dietary fibers, smoking cessation, and control of alcohol consumption [3]. The baseline study will be followed by a report of the effect of such an intervention after a 2-year follow-up.

\section{CONCLUSIONS}

1. About $25.9 \%$ of male and $10.7 \%$ of female Danish seafarers with a mean age of 38.5 years have MS. Due to the major age-related and social gradient, this prevalence of MS is estimated to be higher in the general Danish population.

2. Smoking ashore and on board is slightly higher than that of all Danes. Alcohol intake is very limited onboard, but $18.6 \%$ of Danish seafarers exceed the currently recommended limits ashore.

3. Preventive intervention may target nutrition, exercise, fatigue (e.g. stress, watch systems and sleep quality), smoking, and alcohol habits.

4. Future studies should target seafarers irrespective of nationality, because Asian crews are likely to be in particular risk.

\section{ACKNOWLEDGEMENTS}

The authors wish to thank the participating seafarers and the seafarers' doctors who collected the data for this study. Hanna B. Rasmussen is thanked for support to data management.

This study has received financial support by The Danish Maritime Fund.

\section{REFERENCES}

1. Borch-Johnsen K. The metabolic syndrome in a global perspective. The public health impact: secondary publication. Dan Med Bull 2007; 54: 157-159.

2. Prescott E, Godtfredsen N, Osler M, Schnohr P, Barefoot J. Social gradient in the metabolic syndrome not explained by psychosocial and behavioural factors: evidence from the Copenhagen City Heart Study. Eur J Cardiovasc Prev Rehabil 2007; 14: 405-412.

3. Eckel RH, Grundy SM, Zimmet PZ. The metabolic syndrome. Lancet 2005; 365; 1415-1428.

4. Nichols M, Luengo-Fernandez R, Leal J, Gray A, Scarborough P, Rayner M. European Cardiovascular Disease Statistics 2012. Brussels: European Heart Network, European Society of Cardiology2012.

5. Eapen D, Kalra GL, Merchant N, Arora A, Khan BV. Metabolic syndrome and cardiovascular disease in South Asians. Vasc Health Risk Manag 2009; 5: 731-743.

6. Misra A, Khurana L. Obesity-related non-communicable diseases: South Asians vs White Caucasians. Int J Obes (Lond) 2011; 35: 167-187.

7. Shift work and sleep: optimizing health, safety, and performance. J Occup Environ Med 2011; 53: S1-S10.

8. Almadi T, Cathers I, Chow CM. Associations among work-related stress, cortisol, inflammation, and metabolic syndrome. Psychophysiology 2013; 50: 821-830.

9. Kaltsas G, Vgontzas A, Chrousos G. Fatigue, endocrinopathies, and metabolic disorders. PM R 2010; 2: 393-398.

10. Oldenburg M, Baur X, Schlaich C. Occupational risks and challenges of seafaring. J Occup Health 2010; 52: 249-256.

11. Hansen HL, Tuchsen F, Hannerz H. Hospitalisations among seafarers on merchant ships. Occup Environm Med 2005; 62: 145-150.

12. Kaerlev L, Dahl S, Nielsen PS et al. Hospital contacts for chronic diseases among Danish seafarers and fishermen: a population-based cohort study. Scand J Public Health 2007; 35: 481-489.

13. Hansen HL, Pedersen G. Influence of occupational accidents and deaths related to lifestyle on mortality among merchant seafarers. Int J Epidemiol 1996; 25:1237-1243. 
14. Borch DF, Hansen HL, Jepsen JR. Surveillance of maritime deaths onboard Danish merchant ships. Int Marit Health 2012; 61: 7-16.

15. Hoeyer JL, Hansen HL. Obesity among Danish seafarers. Int Marit Health 2005; 56: 48-55.

16. Hansen HL, Hjarnoe L, Jepsen JR. Obesity continues to be a major health risk for Danish seafarers and fishermen. Int Marit Health 2011; 62: 98-103.

17. Sims EA. Are there persons who are obese, but metabolically healthy? Metabolism 2001; 50: 1499-1504.

18. Arnlov J, Sundstrom J, Ingelsson E, Lind L. Impact of BMI and the metabolic syndrome on the risk of diabetes in middle-aged men. Diabetes Care 2011; 34: 61-65.

19. Hjarnoe L, Leppin A. A risky occupation? (Un)healthy lifestyle behaviors among Danish seafarers. Health Promot Int 2013. Advance access April 28, 2013. DOI: 10.1093/heapro/dat024.

20. Thabit H, Burns N, Shah S et al. Prevalence and predictors of diabetes and cardiometabolic risk among construction workers in Ireland: the Construction Workers Health Trust screening study. Diab Vasc Dis Res 2013; 10: 337-345.

21. Hartley TA, Burchfiel CM, Fekedulegn D, Andrew ME, Knox SS, Violanti JM. Associations between police officer stress and the metabolic syndrome. Int J Emerg Ment Health 2011; 13 : 243-256.

22. Zimmerman FH. Cardiovascular disease and risk factors in law enforcement personnel: a comprehensive review. Cardiol Rev 2012; 20: 159-166.

23. Davila EP, Florez H, Fleming LE et al. Prevalence of the metabolic syndrome among U.S. workers. Diabetes Care 2010; 33: 2390-2395.
24. Kawada T. Predictors of the development of metabolic syndrome in male workers: a 3-year follow-up study. J Occup Environ Med 2012; 54: 292-295.

25. Roberts SB, Krebs N. Can weight management programs in worksites reduce the obesity epidemic? Adv Nutr 2012; 3: 730-731.

26. Cameron AJ, Shaw JE, Zimmet PZ. The metabolic syndrome: prevalence in worldwide populations. Endocrinol Metab Clin North Am 2004; 33: 351-375.

27. Krane-Gartiser K, Breum L, Glumrr C et al. Prevalence of the metabolic syndrome in Danish psychiatric outpatients treated with antipsychotics. Nord J Psychiatry 2011; 65: 345-52.

28. Jeppesen J, Hansen TW, Rasmussen S, Ibsen H, Torp-Pedersen C, Madsbad S. Insulin resistance, the metabolic syndrome, and risk of incident cardiovascular disease: a population-based study. J Am Coll Cardiol 2007; 49: 2112-2119.

29. Brandt LP, Kirk NU, Jensen OC, Hansen HL. Mortality among Danish merchant seamen from 1970 to 1985. Am J Ind Med 1994; 25: 867-876.

30. Hansen HL, Dahl S, Bertelsten B, Brix J. Lifestyle, nutritional status and working conditions of Danish sailors. Travel Med Int 1994; 12: $139-143$.

31. Hansen $\mathrm{HL}$, Jensen J. Female seafarers adopt the high risk lifestyle of male seafarers. Occup Environm Med 1998; 55: 49-51.

32. Takeuchi T, Nakao M, Nomura K, Yano E. Association of metabolic syndrome with smoking and alcohol intake in Japanese men. Nicotine Tob Res 2009; 11: 1093-1098.

33. Misra A, Singhal N, Khurana L. Obesity, the metabolic syndrome, and type 2 diabetes in developing countries: role of dietary fats and oils. J Am Coll Nutr 2010; 29: 289S-301S. 